\title{
Behcet's Disease: New Concepts in Cardiovascular Involvements and Future Direction for Treatment
}

\author{
M. B. Owlia and G. Mehrpoor \\ Division of Rheumatology, Shahid Sadoughi University of Medical Sciences, Yazd, Iran \\ Correspondence should be addressed to M. B. Owlia, bagherowlia@gmail.com \\ Received 17 November 2011; Accepted 15 December 2011 \\ Academic Editors: S. Ceruti and R. Fantozzi
}

Copyright ( $) 2012$ M. B. Owlia and G. Mehrpoor. This is an open access article distributed under the Creative Commons Attribution License, which permits unrestricted use, distribution, and reproduction in any medium, provided the original work is properly cited.

Behcet's disease (BD) is the only systemic vasculitis involving both arteries and vein in any sizes. It frequently encounters in rheumatology clinics. It has some major morbidities and even fatal outcomes in some cases. The aim of this paper is to analyze the main concepts on pathophysiology and treatment options in $\mathrm{BD}$, focusing on cardiovascular aspects, thrombosis, and potential future treatment.

\section{Introduction}

Behcet's disease (BD) is a chronic, relapsing multisystem autoinflammatory condition. It clinically diagnoses with recurrent oral and/or genital aphthosis, mucocutaneous lesions, central nervous system manifestation, and ocular, vascular, articular, gastrointestinal, and inflammatory eye lesions. Autoinflammatory conditions are a group of heritable inflammatory-mediated conditions characterized by idiopathic attacks of systemic inflammation with lack of known-specific antigens and antibodies or immune response [1]. These conditions share in some clinical aspects including uveitis, fever, arthritis, and mucocutanous lesions as seen in hyperimmunoglobulinemia D syndrome, periodic fever syndrome (HIDS), familial Mediterranean fever (FMF), and tumor necrosis factor receptor-associated fever syndrome (TRAPS).

Both genders at the third and fourth decade of life can be affected [2, 3]. Different prevalences of $\mathrm{BD}$ are reported. The highest prevalence was reported in Turkey (40-370 per 100000) [4], while this was 80 per 100000 in Iran [5] and 7 to 8.5 per 100000 in Japan. By contrast, the disease is less common in North America, Northern Europe, USA, UK, and Germany (0.12 to 0.64) [6].

Vascular involvement has been reported in 7.7 to $38 \%$ of BD cases, with mortality of about $20 \%$ in severe cases.
Despite lower sensitivity of this manifestation in $\mathrm{BD}$, its higher specificity with respect to eye and skin involvement merits special consideration for Behcetologists. Venous thrombosis could be as the initial presentation of BD [7]. Both veins and arteries with any size can be affected. Most authors believed that venous manifestation is more common in BD. According to Hamza classification there are five types of vascular involvement in BD (Table 1). Early recognition of vascular lesions is important because it seriously affects $\mathrm{BD}$ prognosis. The leading cause of sudden death in patients with $\mathrm{BD}$ is usually ruptured of a large aortic or arterial aneurysm [8].

We performed a comprehensive search through MEDLINE, Web of Science, Scopus, and Google Scholar for recently published articles, using the following keywords: Behcet's disease, Behcet's syndrome, cardiovascular, thrombosis, aneurysm, pseudoaneurysm, deep vein thrombosis, embolism, heart, vessel, biological therapy, thrombophilia, infliximab, etanercept, rituximab, atherosclerosis, platelet, and aspirin. Most of reviewed articles were from 2000-2011. We emphasized on studies with higher evidence levels and larger sample size cohorts.

The aim of this study is to review the main new concepts on pathophysiology, clinical manifestation, and current and potential future treatment in cardiovascular BD. 
TABLE 1: Hamza classification of vascular involvement in Behcet disease.

\begin{tabular}{ll}
\hline Type & Vascular involvement \\
\hline I & Venous thrombosis \\
II & Arterial thrombosis \\
III & Arterial aneurysm \\
IV & Arterial thrombosis and aneurysm \\
V & Venous thrombosis and arterial lesion \\
\hline
\end{tabular}

\section{Cardiovascular Etiopathogenesis and Pathology}

The real etiopathogenesis of BD is not well understood [9]. As in most autoinflammatory and autoimmune conditions, genetic predisposition and environmental factors may play some role in pathophysiology of BD. HLA-B51expression is believed to be associated with more severe disease in several studies and is related to familial BD [10]. In various studies from Iran, Tunisia, Turkey, Israel, France, and Canada, it was shown that (tumor necrosis factor) TNF-alpha-1031C allele and polymorphism in IL-21, 10, and 8 genes are related to pathogenesis of BD [11-17]. The role of IL-23/IL-17 axis is recently introduced in inducing $\mathrm{BD}[18,19]$.

Delayed-type hypersensitivity to infections such as streptococcus species (especially sanguis) are supposed in part by some authors to be an important factor in inducing BD [20]. These bacterial antigens along with heat shock protein (HSP) $60 / 65 \mathrm{kDa}$ activate T cells to promote inflammatory response in $\mathrm{BD}[9,21]$. Besides from antiinflammatory activities of antibiotics, favorable response of joint, and mucucutaneous manifestations of BD to benzathine penicillin may potentiate the hypothesis of some role for infection [22-24].

Coagulation abnormalities and platelet overactivity may have some additional role on endothelial damage, inflammation and vascular pathologies in BD (Figure 1) [25-27]. Increased levels of nitric oxide (NO) after induction by Interferon-gamma are seen in active BD [28]. In addition, hypovitaminosis $\mathrm{D}$ was shown to be related to immune aberrancy leading to BD [29].

It has been postulated that platelet-neutrophils complexes (PNC) can play an important role in thrombosisinflammation which is seen in some critical vascular events including BD [30-35]. Also it has been shown that inhibition of PNC formation led to marked reduction in pulmonary injuries and improved pulmonary function [33]. Köhler et al. found that PNC formation facilitates transendothelial movement of platelets involving in process of thrombosis inflammation in vitro and in vivo.

Elevation in some markers of endothelial dysfunction (thrombomodulin and adhesion molecules) and low-grade inflammation (proinflammatory cytokines, C-reactive protein, and serum amyloid A) disclose their important role in pathophysiology of most immune-mediated cardiovascular events in BD [36].

Impaired hypothalamus-pituitary-adrenal (HPA) axis which is an important background in most autoimmune

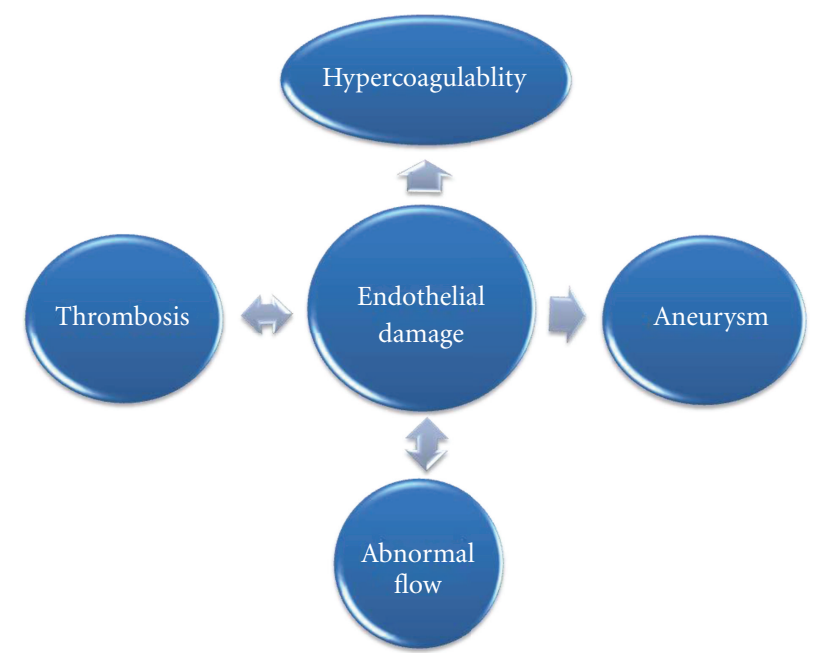

FIgure 1: Correlation between hyperquagulopathy, endothelial damage, thrombosis, aneurysm and abnormal flow in pathophysiology of vascular Behcet diseas.

disease may be involved in etiopathogenesis of $\mathrm{BD}$, while this issue has been less addressed in the literatures. The main reason for this is due to the fact that frequently symptoms of patients will appear after a major or even minor emotional stresses. This incompetent HPA axis may lead to overexpression of proinflammatory cytokines definitely involved in pathogenesis of $\mathrm{BD}$.

The precise pathogenetic mechanism of prothrombotic state in $\mathrm{BD}$ is unknown. It seems that thrombophilic factors could contribute to thrombosis in BD. In addition, similar to the other disorders with increased risk of thrombosis formation, there is endothelial cell injury and hypercoagulable state in BD. Endothelial dysfunction due to antiendothelial cell antibodies and elevated plasma Vascular Endothelial Growth Factor (VEGF) levels lead to microcirculation disturbance and increased blood viscosity and abnormal blood flow [3739]. Furthermore, selectins, a group of adhesion molecules consist of $\mathrm{P}$ and E-selectins that mediate leukocyte adhesion to platelets and endothelium and have a role in thrombogenesis. E-selectin is expressed by activated endothelial cells and P-selectin is synthesized and stored in platelets and endothelial cells. Increased P and E-selectin level in BD was reported in some studies [40-44].

In addition, it has been reported that factor $\mathrm{V}$ Leiden [45-48] may be a factor in the development of thrombotic events in $\mathrm{BD}$. Also other factors which may play some role in the hypercoagulability are protein $\mathrm{C}$ or protein $\mathrm{S}$ deficiency $[49,50]$, impaired fibrinolytic activity, increased homocysteine levels $[51,52]$, decreased thrombomodulin [53], elevated Lipoprotein (a) [54, 55], platelet hyperactivity, high von Willebrand factor antigen, and the presence of antiphospholipid antibodies [56-58]. Dyslipidaemia and predominantly hypertriglyceridemia might also be risk factors. Besides inherent factors inducing thrombophilia in BD; vasculitis and vessel wall inflammations are the other more important factors. Vasculitis can lead to the enhancement of 
platelet aggregation, and an impairment of fibrinolysis resulting in thrombosis [59].

It is well known that platelet is one of the most important components in hemostasis. Following endothelial injury, the first step in thrombosis, formation is the platelet adherence, aggregation and activation. Increased Mean Platelet Volume (MPV), a marker of platelet function, is associated with thrombosis in $\mathrm{BD}[60,61]$. Increased aggregation of platelet in vitro in response to adenosine diphosphate (ADP) and collagen is reported [62].

Cardiovascular pathology in $\mathrm{BD}$ represents a unique spectrum of inflammation, thrombosis and aneurysm. It seems that vasculitis is cornerstone of cardiovascular manifestation in BD. Necrotizing leukocytoclastic or polymorphonuclear (PMN), obliterative perivasculitis and lymphoplasma cell infiltration of capillaries, veins, and arteries, and vasa vasorum (and not vasa nervorum) are the main pathologic features in affected tissues. Infiltration of PMNs is a distinctive pathologic feature of $\mathrm{BD}$ addressing to therapeutic role of PMN inhibiting agents such as colchicines and dapson. Vascular wall destruction due to inflammatory cell infiltration leads to arterial wall weakening and aneurysmal dilatation. In pseudoaneurysm all layers of intima, media, and adventitia are not involved as seen in aneurysmal lesion (Figure 2). Although accelerated atherosclerosis is a major contributor to cardiovascular events in most autoimmune disorders like systemic lupus erythematous and rheumatoid arthritis [63], several studies showed that atherosclerosis is characteristically not increased in $\mathrm{BD}[64,65]$. Despite nonincreased incidence of overt atherosclerosis in BD, intima/media thickness (IMT) is shown to be increased in some studies that may be due to nonatherosclerotic causes of endothelial hyperactivity [66].

\section{Cardiac Manifestations}

Cardiac involvement is among the most life-threatening complications in $\mathrm{BD}$. They include pericarditis, coronary artery stenosis or aneurysm, myocarditis, cardiomyopathy, congestive heart failure, valvular pathology, endocarditis, intracardiac thrombosis, and aneurysm of aorta or its branches [67].

The incidence and nature of the cardiovascular involvement in BD are not yet clearly documented [68]. Heart involvement with frank clinical presentation is rare in $\mathrm{BD}$ [67]. It was reported $1 \%-5 \%$ in a case series while it was $16.5 \%$ in a registry of Behçet autopsy cases in Japan $[69,70]$. Mortality of this complication is relatively high (around $20 \%)$. In addition cardiac involvement in $\mathrm{BD}$ can be seen frequently without symptoms [71].

Pericarditis is the most common type of heart involvement. Acute pericarditis, tamponade, constrictive pericarditis, and even only pericardial effusion without any symptom have been reported [72-75].

Coronary artery disease (CAD) is rare in $\mathrm{BD}$. It is more common in male younger than 40 years old. The incidence of coronary artery aneurysm is $1.5 \%$ to $5 \%$ [76]. CAD can lead to clinical manifestation such as myocardial infarction, silent ischemia, and stable or unstable angina. Aneurysm, stenosis, occlusion, and arteritis are the most common etiologies for $\mathrm{CAD}$ in $\mathrm{BD}$ [77]. Coronary aneurysms are more frequent than the stenosis and can present as acute coronary syndrome and myocardial infarction, but sometimes are symptomatic [78]. Coronary occlusion is attributed to fibrous intimal thickening as a result of local vasculitis [79]. Conventional coronary angiography is the procedure of choice for diagnosis of coronary artery aneurysms. Two forms of aneurysm can be detected by angiography: saccular and fusiform. In general population, acute myocardial infarction (AMI) is always associated with atherosclerotic coronary artery disease. In young adults with myocardial infarction, nonatherosclerotic etiologies such as embolization, trauma, arteritis, spasm, dissection, and congenital abnormalities should be considered. However, in $\mathrm{BD}$, coronary arteritis has been supposed as an independent pathophysiological mechanism for AMI. Coronary arteritis may lead to myocardial infarction, but in some of patients with MI, coronary artery is normal. It seems that severe $\mathrm{BD}$ cases are to be more prone to AMI. It was shown that occlusion is developed as a result of thrombosis formation in CAD, consequently producing AMI [80]. Understanding the etiology of AMI in BD may be important for determination of best treatment strategy. Silent myocardial infarction (SMI) has also been reported in $\mathrm{BD}[81,82]$. The etiology of SMI is not clear, although autonomic nervous dysfunction has been suggested as an etiology. Güllü et al. [82] and Türkölmez et al. [81] reported high prevalence of SMI on their studies (25\% and 19.5\% among 36 and 41 patients, resp.). Myocardial perfusion scintigraphy was recommended by Türkölmez et al. in patients with long lasted BD for screening of SMI.

A few cases with intracardiac thrombus which often preceding other manifestations of $\mathrm{BD}$ have been reported [83]. These thrombi, found mainly in the right ventricle, are often associated with pulmonary artery aneurysm [84]. The reason for predilection to involve right ventricular is still unclear. However, both ventricular involvements have also been reported [85]. Based on autopsy findings, it looks that endomyocardial fibrosis plays a role in the intracardiac thrombus development in some patients [86], but it is not clear whether they are secondary to underlying endocarditis or endomyocardial fibrosis, because in some case reports, a normal underlying myocardium was described [87]. Due to high specificity of right heart thrombus in BD, in any patient with this finding, diagnosis of $\mathrm{BD}$ should be considered $[86,88,89]$. Intracardiac thrombus is the major differential diagnosis when a young patient presents with an intracardiac mass [90]. This makes enormous diagnosis of cardiac myxoma in some instances [91]. It is especially common in young adults BD patients in Middle East [68]. It is difficult to specify the mechanism of intracardiac thrombi formation. Good prognosis has been reported contrary to several recurrences of thrombosis [68]. Intracardiac thrombus can lead to superior vena cava syndrome [90, 92, 93] and pulmonary embolism [83, 94-96].

Endocardial involvement may present with mitral and aortic valve prolapse, mitral or aortic insufficiency, aneurysm of sinus Valsalva, and endocarditis mimicking bacterial 


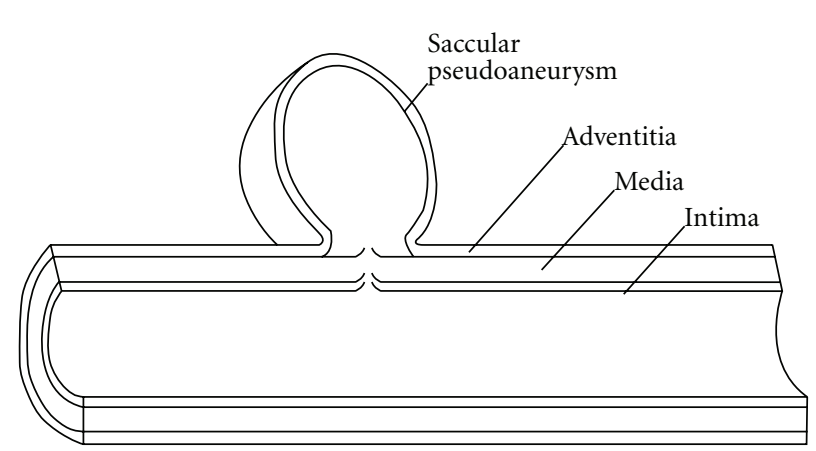

(a)

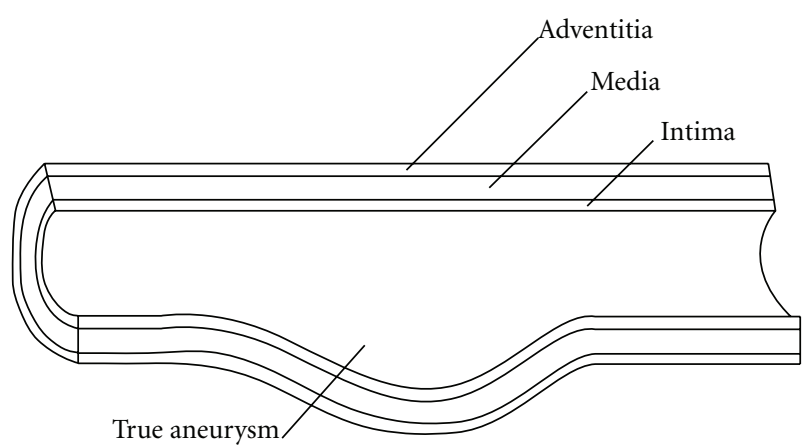

(b)

FIGURE 2: Schematic demonstration of anatomy of pseudoaneurysm (a) and aneurysm (b) in Behcet disease. In true aneurysm all layers of the vessel wall are involved.

endocarditis $[67,97,98]$. The Fibrosis secondary to endocardial involvement in $\mathrm{BD}$ may predispose to intracardiac thrombus formation [99]. It was reported that valvular prolapse including mitral valve prolapse can be related to vasculitis and tissue derangement [97]. Most of the aneurysm of the sinus Valsalva has been found in right coronary sinus which project into the right atrium or ventricle. Usually the problem is diagnosed after rupture of aneurysm. A few cases of sinus Valsalva aneurysm in BD have been reported. Usually they occurred in active phase of $\mathrm{BD}$ and were enlarging progressively. Heart failure due to ruptured aneurysm requires urgent surgical repair.

Conductive abnormalities were also reported in several papers in the past $[100,101]$ that they could directly be attributable or even nonrelated to BD per se.

\section{Thrombosis}

Thrombosis is one of the most common and important features in $\mathrm{BD}$ with prevalence ranging $10-30 \%$ in different studies [102-107]. It was more common in males [102]. In most case series, fever is frequently found in vascular thrombosis along with constitutional symptoms and high acute phase response [108]. Deep vein thrombosis of the lower extremities is the most frequent site for thrombosis in $\mathrm{BD}(60-80 \%$ of vascular lesion) $[103,109]$. Superficial thrombophlebitis is the next common lesion in BD which may occur after venipuncture. This thrombosis has been described at any sites such as cerebral sinuses, intracardiac, renal, ulnar, subclavian, hepatic (Budd-Chiari syndrome) or portal veins, and vena cava [110]. Budd-Chiari syndrome and vena cava thrombosis are associated with increased mortality. One of important clinical entities in vasculo-BD is "venous claudication" due to iliac and/or femoral vein thrombosis [111].

Classic vessel-related lesions in central nervous system (CNS) are related to thrombosis, aneurysms, and frank vasculitis [112]. Both arteries (ischemic and embolic stroke-like picture) and veins (dural sinus thrombosis) are vulnerable in BD. Arterial embolism is also observed in BD secondary to intracardiac thrombosis formation [113]. Most authors believe that venous thrombosis in BD could not result in embolism [114]. In addition, cerebral venous thrombosis (CVT) is a serious manifestation of BD. It was reported that CVT represents $7-30 \%$ of all CNS lesions of $\mathrm{BD}$ in different studies [115-119]. Frequently CVT is seen in a young male patient approximately 5 years after initiation of BD. However, CVT might be the presenting feature in up to $20 \%$ of patients and could be subacute or chronic. Persistent headache, papilledema, nausea, vomiting, and focal deficits are the main complaint among the patients. In $60 \%$ of cases, superior sagittal sinus and transverse sinus are the most common sites of CVT (Figure 3) [120]. The important complication of CVT is severe visual loss. Association between major vessel disorders and CVT has also been described [121]. While parenchymal lesions in CNS are categorized as a nonvascular lesions, but even parenchymal lesions are resulted from some microvascular events [113].

\section{Aneurysm}

Arterial pathology in BD divided into two categories: occlusive or aneurysmal lesion. Although it has been reported that venous involvement is the most common vasculo-Behcet complication but Jamoussi reported that arterial involvement is more frequently seen than the venous complication [122]. The most severe complication is aneurysm formation and rupture. Abdominal aorta is the common site of aneurysm and approximately $60 \%$ of reported arterial lesions associated with BD is aneurysms [123]. Aorta is among the most common affected arteries followed by the pulmonary artery. In thoracoabdominal aorta, the abdominal aorta shows more frequent aneurysm development than the thoracic aorta. Unusual aneurysms and pseudoaneurysms like ulnar, celiac, subclavian, left anterior descending, tibioperoneal, iliac, and superior mesenteric artery aneurysm were reported as rare manifestations of $\mathrm{BD}$ [124-129].

Pulmonary artery aneurysm (PAA) with an associated rate of $1 \%-10 \%$ of patients in $\mathrm{BD}$ is the most common pulmonary lesion [130]. Yekeler and Goueffic believed that $\mathrm{BD}$ is the only vasculitis which could be associated with PAA. PAA is usually occurred in main pulmonary 


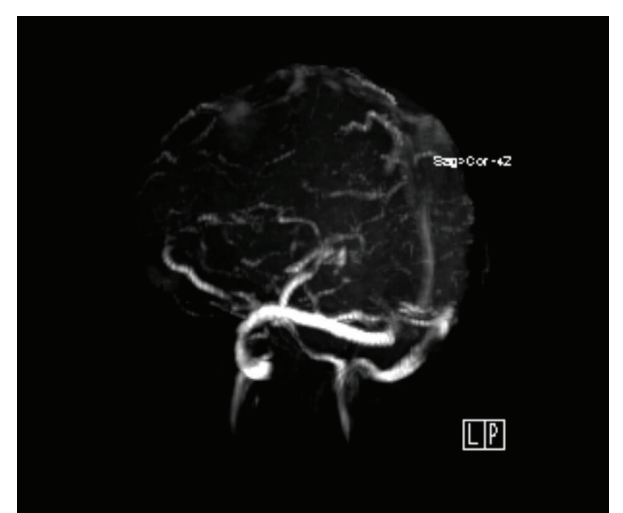

Figure 3: Lateral view of cerebral MRV due to thrombosis in Behcet disease. Superior and inferior sagital and strait sinuses are not visualized due to obliteration by thrombosis (courtesy of Dr. R. Nafisi, radiologist).

arteries. Perihilar or parenchymal opacities can be seen on chest radiographs; however, these radiographic features are not specific and pathognomonic. Ruptured PAA and fatal hemoptysis lead to poor prognosis.

Occurrence of PAA along with deep vein thrombosis is defined as Hughes-Stovin syndrome (HSS), which may be a variant of BD. Less than 40 published cases of HSS have been described. Infections and angiodysplasia are possible causes in etiopathogenesis of HSS. The patients usually present with cough, dyspnea, fever, chest pain, and hemoptysis. Overall, patients with HSS have a poor prognosis. Early diagnosis and treatment may associate with better prognosis.

The occurrence of intracranial aneurysm in BD is very rare (e.g., only one case in 316 and 119 patients was reported in Benamour [131] and Al-Dalaan [106] studies, resp.). Middle cerebral artery is the most common affected vessel and subarachnoid hemorrhage is the most presenting manifestation secondary to aneurysm rupture. Association of extracranial and intracranial aneurysm was reported in several BD cases, also multiplicity almost always is seen in vasculo-Behcet; thus more investigation in a patient with extracranial aneurysm is recommended. The prognosis of aneurysm has been differed due to severity of the hemorrhage and BD activity.

The clinical presentation of aneurysm depends on disease stage and anatomic location of lesion. Most of the time, aortic aneurysms show rapid progression to rupture, and as a result, huge retroperitoneal hematoma or hemoperitoneum is developed as initial manifestations. Aortic aneurysms are often a pseudoaneurysm and usually originate from defects located in the posterior or lateral walls of normally sized aorta and then extend into the adjacent retroperitoneal space.

Angiography is the best method in diagnosis of aneurysm and pseudoanurysm, but in BD the risk of new aneurysm formation is high. Therefore noninvasive methods such as digital subtraction angiography, contrast-enhanced tomography and magnetic resonance angiography are the other methods which have been used safely.

The pathogenesis of aneurysm in BD differs from those of atherosclerotic aneurysms. Vasculitis in BD leads to destruction of the media, arterial dilatation and fibrosis. Inflammatory obliteration of the vasa vasorum and consequent transmural necrosis may develop a pseudoanurysm or rupture an arterial wall.

An important characteristic of aneurysm in $\mathrm{BD}$ is predilection for the recurrence, which can occur in different locations.

Matrix metalloproteinase proteins (MMP) which play an important role in tissue remodeling and destruction of extracellular matrix components are thought to have significant role in aneurysm formation. Pay et al. reported that serum level of MMP-9 and MMP-2 are important marker in vasculo-Behcet [132].

\section{Treatment}

6.1. General Considerations. Behcet's disease is a condition without known-specific etiology and evidence that supports the immunologic basis it. Some evidence addresses infectious trigger for it. Therefore, cornerstone of medical management is manipulation of immune system and administering agents against some putative microorganisms and finally surgical intervention in case of vascular complications.

Managing vascular events in BD is debating [133] and very important to all clinical disciplines including vascular rheumatology, cardiovascular medicine, vascular surgery, general internal medicine, general and interventional radiology, and also thrombologists. Due to early diagnosis, aggressive treatments and new techniques of vascular surgery, the prognosis of large vessel involvement in $\mathrm{BD}$ is improving [134].

Few double blind controlled trials were presented, denoting $\mathrm{BD}$ treatment. Most trials with new drugs are as case reports or small case series. The newest EULAR recommendations deal with emerging advances in management of BD. Treatment plan is generally based on the symptom(s), the organ involved, and severity of conditions that should be tailored individually [135].

As mentioned earlier, BD is a multifeature condition. In the next part, we emphasize on management of highly morbid events or life threatening vascular BD.

\subsection{Antiinflammatory and Cytotoxic Agents}

6.2.1. Glucocorticoids (GCs). They are the pillar of management in any organ involvement in autoinflammatory and autoimmune disease; therefore corticosteroids are administered for years in almost any organ involvement in $\mathrm{BD}$ with dramatic response in most cases. Liberal use of corticosteroids in 1950s led to severe and widespread adverse reactions. So strategies to minimizing these side effects have been suggested then after. Administering the "minimum effective dose" (not traditional textbook based doses) tailored for each individual patient could be rational in handling with corticosteroids.

6.2.2. Azathioprine. One of the agents most studied in randomized controlled trials [136] and nonrandomized trials in 
BD is azathioprine [137-139] and almost all of them reported good clinical response with negligible adverse effects. It does not mean that this agent is the utopian agent in BD. Our anecdotal reports from Iran do not match with this evidence. Despite EULAR recommendations conducted by Hatemi et al. denoting use of azathioprine in neurologic involvement in $\mathrm{BD}$, we hardly use this agent in major neurologic manifestations in our center (and also in Iran) due to uncertainty or lack of clinical benefit and cytopenia in tolerable doses in our practice.

6.2.3. Cyclophosphamide. It is the first line cytotoxic agent in life threatening vascular events in BD. The EULAR recommended this agent in both arterial (aneurysm) and venous (thrombosis) involvement in central or peripheral vascular bed. Its side effects of leukopenia, hair loss, and anorexia are reported to be nonsignificant.

6.2.4. Colchicine. The other most common systemic agent used in BD iscolchicine. The mechanism of action for colchicine is not fully understood, but it is shown that the drug accumulates mostly in neutrophils and interferes with microtubule assembly. Dosage adjustment in patients with hepatic and or renal dysfunction is mandatory. Colchicine is believed to not only prevent and treat oral and genital aphthi and uveitis but also is used to prevent recurring intracardiac thrombus in BD. Similarly it is used for some other autoinflammatory conditions like FMF, pyoderma gangrenosum, and other PMN-mediated conditions like Sweet's syndrome [140]. Therefore colchicine should be considered as a safe systemic disease modifying antirheumatic drug (DMARD) in any patient with potentially active BD. Alternatively, considering infiltration of neutrophils in affected vessel wall, doxycycline, a matrix metaloproteinase inhibitor was used in a 2 weeks period after surgery of abdominal aortic aneurysm with better results than placebo [141].

6.2.5. Cyclosporine A. This agent with inhibition of IL-2 and IL-17 is a powerful drug in controlling BD. Most studies are focused on eye (uveitis rather retinal vasculitis) in BD. Thalidomide, an old drug which discovered in 1950s, revisited in recent years as a good antiinflammatory in conditions like aphthous ulcerations, HIV-associated cachexia, inflammatory bowel diseases, and mucocutaneous and intestinal $\mathrm{BD}$ with mechanism of inhibitions of angiogenesis and TNFalpha $[142,143]$.

6.3. Anticoagulation and Antiplatelet Agents. As all clinicians know, standard of care in deep vein thrombosis is anticoagulation in almost all cases. Even there are some indications to thrombolytic therapy in some selected cases of DVTs. The challenging issue is holding anticoagulation in setting of $\mathrm{BD}$ complicated with DVT due to lack of risk of embolic events as supposed by Caspary [144]. We emphasize that this notion is based on category IV evidence of expert opinions. The authors of this review believe that inflammation is an additional feature of BD complicated with thrombosis. Presence of several thrombophilia states in $\mathrm{BD}[25,58,145,146]$ may offset in part the theory of adhering clot to highly inflammatory veins with no risk of embolisation. In our interdisciplinary discussion, we argued about cases in whom repeated attacks of DVT may precede months or years before full-picture $\mathrm{BD}$ and despite the same story for pathophysiology of DVT in these cases, it seems not to prudent withholding anticoagulation in these cases. In addition, we believe any mentioned and wellaccepted risk of major bleeding in routine anticoagulation therapies (about 7\%) may be due to any underlying occult vascular pathologies such as hidden aneurysms or vascular disintegrities like subclinical BD. Saadoun et al. showed that anticoagulation is not only an effective but also a safe treatment in cerebral venous thrombosis [115]. It seems that thrombophilia in BD is a sophisticated process of intervening inherent or hereditary condition, endothelial hyperactivity, and low-grade inflammation [110]. Therefore, it is better to just recommend management of DVT in BD to be accomplished by highly expert physicians and not to discourage anticoagulation $[147,148]$ even in pediatric BD except for pulmonary arterial involvement [149]. Some authors limit control of inflammation for the purpose of prevention of thrombosis rather than treatment of it and handling complicated cases of cerebral sinus, vein and pulmonary vein thrombosis is based on per-case decision made by a multidisciplinary therapeutic team sometimes necessitating more aggressive treatments such as local thrombolysis or surgical interventions.

Regarding Intracardiac thrombus, some authors experienced successful thrombolytic therapy in the case of recurrent right ventricular thrombosis $[150,151]$. Khammar and some other authors suggested colchicine, anticoagulant therapy, and corticosteroids for intracardiac thrombosis in BD $[84,152]$.

6.4. Neurovascular BD. In the case of neurovascular $\mathrm{BD}$ treatment, (in contrary to eye, joint and mucocutaneous studies with level Ib evidence) there is no high-quality controlled trials and almost all studies are case-control or comparative (level III) [114].

Benign vascular headache in $\mathrm{BD}$ is managed conservatively as usual migraine [153]. In CVT, some authors use anticoagulants along with short course glucocorticoids and the others manage it as other parenchymal brain disease in BD. In the newest recommendation, EULAR did not address separately to CVT regarding anticoagulation usage but recommended corticosteroids in dural sinus thrombosis. It has also been emphasized that in CNS BD, cyclosporine A should be withheld except in patients with concomitant eye involvement. This is due to neurotoxicities of cyclosporine in several reports. Vascular CNS aneurysms are managed as in other locations.

6.5. Role of Surgery in Management of BD. Surgical repair is the standard care in cases of organ threatening aneurysmal dilatation, stenosis, or obstruction of clinically significant arteries. In some cases, ligation of affected vessel (mostly 
peripheral ones) is mandatory even in the cases of pulmonary artery [154, 155]. Endovascular approach is a minimally invasive technique for aneurysm repair and is growingly advised by some authors $[125,134,156]$. In $\mathrm{BD}$, this technique has less complications and better results comparing to atherosclerotic lesions [157]. Endarterectomy was performed in rare incidence of bilateral common carotid artery occlusion and chronic thromboembolic pulmonary hypertension secondary to $\mathrm{BD}[158,159]$. Other approach to some kinds of aneurysms is percutaneous embolization of individual aneurysm using substances like n-butyl cyanoacrylate [160]. The most frequently encountered postoperative complication was anastomotic pseudoaneurysm $[125,161]$. Percutaneous transluminal stent angioplasty was successfully used by Han et al. in BD complicated with BuddChiari syndrome [162]. This is important to mention that systemic (and/or local) inflammation should be controlled before any elective surgical intervention. Liu et al. used medical therapy after vascular surgery with similar good results [163]. Conventional immunosuppressive drugs are frequently used as premedication to operative surgery [164].

6.6. Biologic Agents. Biologic agents are emerged in recent decades and are targeted drugs against specific mediators of inflammations. In general, biologic agents are the second choice in cases of BD refractory to conventional immunosuppression [165]. In one study, Baki et al. used infliximab de novo without preceding glucocorticoids and cyclophosphamide in a man with PAA and reported complete remission in two years [166].

The most popular biologic agents are agents against TNF-alpha (infliximab, etanercept and adalimumab), Bcell depleting agents (rituximab), and specific monoclonal antibodies to interleukin (IL)-1 (anakinra), IL-6. Most of studies on infliximab deal with inflammatory eye disease in BD. Considering the role of TNF-alpha in triggering prothrombotic adhesion molecules, using TNF blocking agents could be theoretically of some interest in vasculo$\mathrm{BD}$. Infliximab was used in two cases of PAA (with intracardiac thrombosis), one case with femoral profunda artery aneurysm and two cases with magic syndrome with more than a year of complete remission [166-168]. Employing TNF (and probably other biological agents) in thrombosis of BD was disappointing with especial regard to potential prothrombotic activities and predisposition to frequent autoantibody formation (notably anticardiolipin) of these agents [169].

Infliximab was used in several studies as an agent to improve endothelia dysfunction and suppress low-grade inflammation in the major cases of cardiovascular burden in most autoimmune and autoinflammatory conditions [36, 170, 171].

Adalimumab is another TNF blocking agents which was used in a 43 years old man with PAA. Neither etanercept nor rituximab is reported to be useful in aneurysmal type $\mathrm{BD}$ so far. In recent EULAR recommendations little information is provided regarding these agents in cardiovascular BD. In a recent systematic review the effectiveness of targeted agents are discussed in autoimmune posterior uveitis.

Our search results showed only two studies (both from Iran) addressing the use of rituximab in retinal vasculitis in $\mathrm{BD}$ and both had favorable response $[172,173]$ and several trials mostly as case reports with etanercept uveoretinal involvement even in juvenile BD $[174,175]$. The reason for the far less studies on biological agents in vascular BD could be due to rather less frequent clinical vascular events and limited time for multiple drug trials with newly lunched drugs due to emergent nature of vasculo-Behcet.

Dyslipidemia, a known risk factor for cardiovascular events in both autoimmune conditions and general population, is accelerated with most biologic agents except for adalimumab, rituximab, and etanercept [176].

Interferon alpha, a natural glycoproteins that has antiproliferative and antiviral properties, is used in retinal vasculitis [177]. In a study it was shown that granulocytapheresis is more beneficial in 14 cases with long duration of $\mathrm{BD}$ with uveoretinitis [178]. In addition, hematopoetic stem cell transplantation was used in several cases with necrotizing vasculitis including three cases with $\mathrm{BD}$ with inconsistent clinical results [179].

6.7. Future Direction in Managing Vascular BD. As optimum management in $\mathrm{BD}$ is not achieved yet, future direction in treating $\mathrm{BD}$ could be focused on better understanding of common pathways in pathophysiology of vascular and nonvascular BD. No doubt is about the future role of biologic agents and targeted agents against proinflammatory cytokines such as IL-15, 17, 21, and adhesion molecules in controlling BD. Using biological agents targeting TNF-alpha may improve endothelial dysfunction responsible for more features of BD. Addressing many disease flare-ups after major or even minor physical or emotional stressors, we should also emphasize on potential therapeutic role of HPA axis support to prevent and control BD. Taking into consideration the important role of activated platelets and unique thrombosisinflammation relationship in $\mathrm{BD}$, more clinical application of antiplatelet (aspirin, clopidegrel) solely or in combination with colchicine as a PMN inhibitor is justified [31]. Role of statins as lipid lowering and antiinflammatory agents and improving endothelial dysfunction in $\mathrm{BD}$ could be matter of future studies for clinical use [180]. Detection of possible putative triggering microorganism(s) could direct treatment to some specific antibiotics and even categorize $\mathrm{BD}$ as a potentially infectious disease.

\section{Acknowledgment}

The authors thankfully appreciate Professor F. Davatchi for his kind support and Mr. M. R. Fahimi for producing Figure 2.

\section{References}

[1] A. Gül, "Behçet's disease as an autoinflammatory disorder," Current Drug Targets: Inflammation and Allergy, vol. 4, no. 1, pp. 81-83, 2005. 
[2] H. Yazici, H. Pazarli, and S. Yurdakul, "Influence of age of onset and patient's sex on the prevalence and severity of manifestations of Behcet's syndrome," Annals of the Rheumatic Diseases, vol. 43, no. 6, pp. 783-789, 1984.

[3] C. C. Zouboulis, "Epidemiology of Adamantiades-Behcet's disease," Annales de Medecine Interne, vol. 150, no. 6, pp. 488498, 1999.

[4] F. Erkan, A. Gül, and E. Tasali, "Pulmonary manifestations of Behçet's disease," Thorax, vol. 56, no. 7, pp. 572-578, 2001.

[5] F. Davatchi, A. R. Jamshidi, A. T. Banihashemi et al., "WHOILAR COPCORD study (stage 1, urban study) in Iran," Journal of Rheumatology, vol. 35, no. 7, pp. 1384-1390, 2008.

[6] D. Mendes, M. Correia, M. Barbedo et al., "Behçet's diseasea contemporary review," Journal of Autoimmunity, vol. 32, no. 3-4, pp. 178-188, 2009.

[7] T. Akpolat, Y. Koç, I. Yeniay et al., "Familial Behçet's disease," The European journal of medicine, vol. 1, no. 7, pp. 391-395, 1992.

[8] E. J. Chae, K. H. Do, J. B. Seo et al., "Radiologic and clinical findings of Behçet disease: comprehensive review of multisystemic involvement," Radiographics, vol. 28, no. 5, p. e31, 2008.

[9] C. Mendoza-Pinto, M. García-Carrasco, M. JiménezHernández et al., "Etiopathogenesis of Behcet's disease," Autoimmunity Reviews, vol. 9, no. 4, pp. 241-245, 2010.

[10] I. Fresko, M. Soy, V. Hamuryudan et al., "Genetic anticipation in Behcet's syndrome," Annals of the Rheumatic Diseases, vol. 57, no. 1, pp. 45-48, 1998.

[11] G. Geri, B. Terrier, M. Rosenzwajg et al., "Critical role of IL-21 in modulating TH17 and regulatory T cells in Behet disease," Journal of Allergy and Clinical Immunology, vol. 128, no. 3, pp. 655-664, 2011.

[12] Z. Touma, C. Farra, A. Hamdan et al., “TNF polymorphisms in patients with Behcet disease: a meta-analysis," Archives of Medical Research, vol. 41, no. 2, pp. 142-146, 2010.

[13] M. Bonyadi, Z. Jahanafrooz, M. Esmaeili et al., "TNF- $\alpha$ gene polymorphisms in Iranian Azeri Turkish patients with Behcet's Disease," Rheumatology International, vol. 30, no. 2, pp. 285-289, 2009.

[14] A. Akman, N. Sallakci, H. Kacaroglu et al., "Relationship between periodontal findings and the TNF- $\alpha$ Gene 1031T/C polymorphism in Turkish patients with Behçet's disease," Journal of the European Academy of Dermatology and Venereology, vol. 22, no. 8, pp. 950-957, 2008.

[15] I. Krause and A. Weinberger, "Behçet's disease," Current Opinion in Rheumatology, vol. 20, no. 1, pp. 82-87, 2008.

[16] M. Kamoun, H. Chelbi, M. H. Houman, J. Lacheb, and K. Hamzaoui, "Tumor necrosis factor gene polymorphisms in Tunisian patients with Behçet's disease," Human Immunology, vol. 68, no. 3, pp. 201-205, 2007.

[17] A. Akman, N. Sallakci, M. Coskun et al., "TNF- $\alpha$ gene $1031 \mathrm{~T} / \mathrm{C}$ polymorphism in Turkish patients with Behçet's disease," British Journal of Dermatology, vol. 155, no. 2, pp. 350-356, 2006.

[18] R. X. Leng, G. M. Chen, H. F. Pan, and D. Q. Ye, "The role of IL-23/IL-17 axis in the etiopathogenesis of Behçet's disease," Clinical rheumatology, vol. 29, no. 10, p. 1209, 2010.

[19] N. S. Ekinci, E. Alpsoy, A. A. Karakas, S. B. Yilmaz, and O. Yegin, "IL-17A has an important role in the acute attacks of behçet's disease," Journal of Investigative Dermatology, vol. 130, no. 8, pp. 2136-2138, 2010.

[20] F. Kaneko, A. Togashi, S. Saito et al., "Behçet's disease (Adamantiades-Behçet's disease)," Clinical and Developmental Immunology, vol. 2011, Article ID 681956, 7 pages, 2011.
[21] G. Mumcu, N. Inanc, S. Yavuz, and H. Direskeneli, "The role of infectious agents in the pathogenesis, clinical manifestations and treatment strategies in Behçet's disease," Clinical and Experimental Rheumatology, vol. 25, no. 4, pp. S27-S33, 2007.

[22] M. M. Al-Waiz, K. E. Sharquie, M. H. A-Qaissi, and R. K. Hayani, "Colchicine and benzathine penicillin in the treatment of Behçet disease: a case comparative study," Dermatology Online Journal, vol. 11, no. 3, article no. 3, 2005.

[23] H. Demiroglu, O. I. Özcebe, I. Barista, S. Dündar, and B. Eldem, "Interferon alfa-2b, colchicine, and benzathine penicillin versus colchicine and benzathine penicillin in Behcet's disease: a randomised trial," Lancet, vol. 355, no. 9204, pp. 605-609, 2000.

[24] M. Çalgüneri, S. Kiraz, I. Ertenli, M. Benekli, Y. Karaarslan, and I. Çelik, "The effect of prophylactic penicillin treatment on the course of arthritis episodes in patients with Behçet's disease: a randomized clinical trial," Arthritis and Rheumatism, vol. 39, no. 12, pp. 2062-2065, 1996.

[25] M. La Regina, F. Orlandini, D. Prisco, and F. Dentali, "Homocysteine in vascular behçet disease: a meta-analysis," Arteriosclerosis, Thrombosis, and Vascular Biology, vol. 30, no. 10, pp. 2067-2074, 2010.

[26] J. Shanker, A. Y. Gasparyan, G. D. Kitas, and V. V. Kakkar, "Platelet function and antiplatelet therapy in cardiovascular disease: implications of genetic polymorphisms," Current Vascular Pharmacology, vol. 9, no. 4, pp. 479-489, 2011.

[27] A. Y. Gasparyan, L. Ayvazyan, D. P. Mikhailidis, and G. D. Kitas, "Mean platelet volume: a link between thrombosis and inflammation?" Current Pharmaceutical Design, vol. 17, no. 1, pp. 47-58, 2011.

[28] H. Belguendouz, D. Messaoudène, K. Lahmar et al., "Interferon- $\gamma$ and nitric oxide production during Behçet uveitis: immunomodulatory effect of interleukin-10," Journal of Interferon and Cytokine Research, vol. 31, no. 9, pp. 643$651,2011$.

[29] K. Hamzaoui, I. B. Dhifallah, E. Karray, F. H. Sassi, and A. Hamzaoui, "Vitamin D modulates peripheral immunity in patients with Behçet's disease," Clinical and Experimental Rheumatology, vol. 28, no. 4, pp. S50-S57, 2010.

[30] D. Köhler, A. Straub, T. Weissmüller et al., "Phosphorylation of vasodilator-stimulated phosphoprotein prevents plateletneutrophil complex formation and dampens myocardial ischemia-reperfusion injury," Circulation, vol. 123, no. 22, pp. 2579-2590, 2011.

[31] G. E. Pamuk, Ö. N. Pamuk, H. Örüm, M. Demir, B. Turgut, and N. Çakir, "Might platelet-leucocyte complexes be playing a role in major vascular involvement of Behçet's disease? A comparative study," Blood Coagulation and Fibrinolysis, vol. 21, no. 2, pp. 113-117, 2010.

[32] G. E. Pamuk, B. Turgut, Ö. N. Pamuk, Ö. Vural, M. Demir, and N. Çakr, "Increased circulating platelet-leucocyte complexes in patients with primary Raynaud's phenomenon and Raynaud's phenomenon secondary to systemic sclerosis: a comparative study," Blood Coagulation and Fibrinolysis, vol. 18, no. 4, pp. 297-302, 2007.

[33] A. Zarbock, K. Singbartl, and K. Ley, "Complete reversal of acid-induced acute lung injury by blocking of plateletneutrophil aggregation," Journal of Clinical Investigation, vol. 116, no. 12, pp. 3211-3219, 2006.

[34] D. T. Ertugrul, A. Gürsoy, M. Yücel et al., "Effects of raloxifene on platelet functions in patients with postmenopausal osteoporosis," Platelets, vol. 17, no. 6, pp. 351-353, 2006. 
[35] D. J. H. McCabe, P. Harrison, I. J. Mackie et al., "Increased platelet count and leucocyte-platelet complex formation in acute symptomatic compared with asymptomatic severe carotid stenosis," Journal of Neurology, Neurosurgery and Psychiatry, vol. 76, no. 9, pp. 1249-1254, 2005.

[36] B. C. Van Bussel, F. Schouten, R. M. Henry et al., "Endothelial dysfunction and low-grade inflammation are associated with greater arterial stiffness over a 6-year period," Hypertension, vol. 58, no. 4, pp. 588-595, 2011.

[37] J. A. Clayton, D. Chalothorn, and J. E. Faber, "Vascular endothelial growth factor-a specifies formation of native collaterals and regulates collateral growth in ischemia," Circulation Research, vol. 103, no. 9, pp. 1027-1036, 2008.

[38] E. Bozoglu, A. Dinc, H. Erdem, S. Pay, I. Simsek, and I. H. Kocar, "Vascular endothelial growth factor and monocyte chemoattractant protein-1 in Behçet's patients with venous thrombosis," Clinical and Experimental Rheumatology, vol. 23, no. 4, pp. S42-S48, 2005.

[39] K. W. Lee, G. Y. H. Lip, and A. D. Blann, "Plasma angiopoietin-1, angiopoietin-2, angiopoietin receptor Tie2 , and vascular endothelial growth factor levels in acute coronary syndromes," Circulation, vol. 110, no. 16, pp. 23552360, 2004.

[40] Y. Turkoz, C. Evereklioglu, A. Özkiriş et al., "Serum levels of soluble P-selectin are increased and associated with disease activity in patients with Behçet's syndrome," Mediators of Inflammation, vol. 2005, no. 4, pp. 237-241, 2005.

[41] R. A. Sari, A. Kiziltunç, S. Taysý, S. Akdemýr, and M. Gündoğdu, "Levels of soluble E-selectin in patients with active Behçet's disease," Clinical Rheumatology, vol. 24, no. 1, pp. 55-59, 2005.

[42] S. E. Tunc, K. Aksu, G. Keser et al., "Platelet-activating factor and P-selectin activities in thrombotic and nonthrombotic Behçet's patients," Rheumatology International, vol. 25, no. 5, pp. 326-331, 2005.

[43] S. Haznedaroğlu, Y. Karaaslan, Y. Büyükaşik et al., "Selectin adhesion molecules in Behcet's disease," Annals of the Rheumatic Diseases, vol. 59, no. 1, pp. 61-63, 2000.

[44] G. Triolo, A. Accardo-Palumbo, G. Triolo, M. C. Carbone, A. Ferrante, and E. Giardina, "Enhancement of endothelial cell E-selectin expression by sera from patients with active Behcet's disease: moderate correlation with anti- endothelial cell antibodies and serum myeloperoxidase levels," Clinical Immunology, vol. 91, no. 3, pp. 330-337, 1999.

[45] F. Batioğlu, L. S. Atmaca, H. G. Karabulut, and D. B. Sayin, "Factor V Leiden and prothrombin gene G20210A mutations in ocular Behçet disease," Acta Ophthalmologica Scandinavica, vol. 81, no. 3, pp. 283-285, 2003.

[46] A. Gurgey, G. Balta, and A. Boyvat, "Factor V Leiden mutation and PAI-1 gene 4G/5G genotype in thrombotic patients with Behcet's disease," Blood Coagulation and Fibrinolysis, vol. 14, no. 2, pp. 121-124, 2003.

[47] L. Mammo, A. Al-Dalaan, S. S. Bahabri, and J. N. Saour, "Association of factor V Leiden with Behcet's disease," Journal of Rheumatology, vol. 24, no. 11, pp. 2196-2198, 1997.

[48] A. Gül, U. Özbek, C. Öztürk, M. Inanç, M. Koniçe, and T. Özcelik, "Coagulation factor V gene mutation increases the risk of venous thrombosis in Behcet's disease," British Journal of Rheumatology, vol. 35, no. 11, pp. 1178-1180, 1996.

[49] R. Mader, Z. Michael, M. Adawi, R. Mader, and I. Lavi, "Thrombophilic factors and their relation to thromboembolic and other clinical manifestations in Behcet's disease," Journal of Rheumatology, vol. 26, no. 11, pp. 2404-2408, 1999.
[50] N. Lenk, G. Özet, N. Alli, Ö. Çoban, and S. Erbaşi, "Protein $\mathrm{C}$ and protein $\mathrm{S}$ activities in Behcet's disease as risk factors of thrombosis," International Journal of Dermatology, vol. 37, no. 2, pp. 124-125, 1998.

[51] F. Shahram, A. Faridar, M. G. Hamedani et al., "Plasma homocysteine level in patients with Behcet's disease with or without thrombosis," Archives of Iranian Medicine, vol. 13, no. 6, pp. 476-481, 2010.

[52] K. Aksu, N. Turgan, F. Oksel et al., "Hyperhomocysteinaemia in Behçet's disease," Rheumatology, vol. 40, no. 6, pp. 687690, 2001.

[53] S. Demirer, N. Şengül, M. A. Yerdel et al., "Haemostasis in patients with Behcet's disease," European Journal of Vascular and Endovascular Surgery, vol. 19, no. 6, pp. 570-574, 2000.

[54] S. Esmat, H. El Sherif, S. Anwar, I. Fahmy, M. Elmenyawi, and O. Shaker, "Lipoprotein (a) and nitrites in Behcet's disease: relationship with disease activity and vascular complictions," European Journal of Dermatology, vol. 16, no. 1, pp. 67-71, 2006.

[55] Ö. Gürbüz, Y. Özdemir, C. B. Coşar, and G. Kural, "Lipoprotein (a) in Behçet's disease as an indicator of disease activity and in thrombotic complications," European Journal of Ophthalmology, vol. 11, no. 1, pp. 62-65, 2001.

[56] S. Tokay, H. Direskeneli, S. Yurdakul, and T. Akoglu, "Anticardiolipin antibodies in Behçet's disease: a reassessment," Rheumatology, vol. 40, no. 2, pp. 192-195, 2001.

[57] A. N. Al-Dalaan, S. R. Al-Ballaa, M. A. Al-Janadi, S. Bohlega, and S. Bahabri, "Association of anti-cardiolipin antibodies with vascular thrombosis and neurological manifestation of Behcet's disease," Clinical Rheumatology, vol. 12, no. 1, pp. 28-30, 1993.

[58] M. Zivkovic, M. Zlatanovic, G. Zlatanovic, J. DjordjevicJocic, and S. Cekic, "Anticardiolipin antibodies in patients with Behcet's disease," Bosnian Journal of Basic Medical Sciences, vol. 11, no. 1, pp. 58-61, 2011.

[59] S. Yurdakul and H. Yazici, "Behçet's syndrome," Best Practice and Research: Clinical Rheumatology, vol. 22, no. 5, pp. 793809, 2008.

[60] N. Acikgoz, Y. Karincaoglu, N. Ermis et al., "Increased mean platelet volume in Behçet's disease with thrombotic tendency," The Tohoku journal of experimental medicine, vol. 221, no. 2, pp. 119-123, 2010.

[61] Y. Park, N. Schoene, and W. Harris, "Mean platelet volume as an indicator of platelet activation: methodological issues," Platelets, vol. 13, no. 5-6, pp. 301-306, 2002.

[62] S. Kamath, A. D. Blann, and G. Y. H. Lip, "Platelet activation: assessment and quantification," European Heart Journal, vol. 22, no. 17, pp. 1561-1571, 2001.

[63] A. Y. Gasparyan, A. Stavropoulos-Kalinoglou, D. P. Mikhailidis, T. E. Toms, K. M. J. Douglas, and G. D. Kitas, "The rationale for comparative studies of accelerated atherosclerosis in rheumatic diseases," Current Vascular Pharmacology, vol. 8, no. 4, pp. 437-449, 2010.

[64] E. Seyahi, S. Ugurlu, R. Cumali et al., "Atherosclerosis in Behçet's syndrome," Seminars in Arthritis and Rheumatism, vol. 38, no. 1, pp. 1-12, 2008.

[65] M. A. Öztürk, S. Ünverdi, S. O. Oktar et al., "Vascular endothelial growth factor and carotid intima-media thickness in patients with Behç's disease," Clinical Rheumatology, vol. 27, no. 8, pp. 961-966, 2008.

[66] S. N. Hong, J. C. Park, N. S. Yoon et al., "Carotid artery intima-media thickness in Behcet's disease patients without significant cardiovascular involvement," Korean Journal of Internal Medicine, vol. 23, no. 2, pp. 87-93, 2008. 
[67] M. Marzban, M. H. Mandegar, A. Karimi et al., "Cardiac and great vessel involvement in 'Behcet's disease," Journal of Cardiac Surgery, vol. 23, no. 6, pp. 765-768, 2008.

[68] Y. Sezen, H. Buyukatipoglu, Z. Kucukdurmaz, and R. Geyik, "Cardiovascular involvement in Behçet's disease," Clinical Rheumatology, vol. 29, no. 1, pp. 7-12, 2010.

[69] B. Wechsler, L. T. H. Du, and E. Kieffer, "Cardiovascular manifestations of Behcet's disease," Annales de Medecine Interne, vol. 150, no. 7, pp. 542-554, 1999.

[70] S. Lakhanpal, K. Tani, and J. T. Lie, "Pathologic features of Behcet's syndrome: a review of Japanese autopsy registry data," Human Pathology, vol. 16, no. 8, pp. 790-795, 1985.

[71] C. Nojiri, M. Endo, and H. Koyanagi, "Conduction disturbance in Behcet's disease. Association with ruptured aneurysm of the sinus of Valsalva into the left ventricular cavity," Chest, vol. 86, no. 4, pp. 636-638, 1984.

[72] C. M. Kwon, S. H. Lee, J. H. Kim et al., "A case of Behçet's disease with pericarditis, thrombotic thrombocytopenic purpura, deep vein thrombosis and coronary artery pseudo aneurysm," Korean Journal of Internal Medicine, vol. 21, no. 1, pp. 50-56, 2006.

[73] B. Ökcun, T. Baran, E. Babalik, and S. Kücükoglu, "Multichamber masses and constrictive pericarditis in Behçet's disease," Clinical and Experimental Rheumatology, vol. 21, no. 4, supplement 30, p. S55, 2003.

[74] G. Vaiopoulos, G. Stamatelos, A. Aessopos, S. Michael, G. Christopoulos, and P. Kaklamanis, "Asymptomatic pericarditis in Adamantiadis-Behcet's disease," Clinical and Experimental Rheumatology, vol. 13, no. 5, pp. 649-651, 1995.

[75] J. Lanfranchi, M. Robineau, P. Delaporte, R. N. Sachs, and J. Salama, "Acute pericarditis and Behçet's disease," La Nouvelle presse medicale, vol. 10, no. 24, pp. 2038-2039, 1981.

[76] G. E. Pineda, S. Khanal, M. Mandawat, and J. Wilkin, "Large atherosclerotic left main coronary aneurysm-a case report and review of the literature," Angiology, vol. 52, no. 7, pp. 501-504, 2001.

[77] D. Ioakimidis, C. Georganas, C. Panagoulis et al., "A case of Adamantiadis-Behcet's syndrome presenting as myocardial infarction," Clinical and Experimental Rheumatology, vol. 11, no. 2, pp. 183-186, 1993.

[78] H. Bardakci, U. Kervan, E. Boysan, L. Birincioglu, and A. Cobanoglu, "Aortic arch aneurysm, pseudocoarctation, and coronary artery disease: in a patient with Behçet's syndrome," Texas Heart Institute Journal, vol. 34, no. 3, pp. 363-365, 2007.

[79] M. H. Song, T. Watanabe, and H. Nakamura, "Successful offpump coronary artery bypass for Behcet's disease," Annals of Thoracic Surgery, vol. 77, no. 4, pp. 1451-1454, 2004.

[80] J. Zhuang, S. Wang, Z. Zhang, S. Zeng, Y. Shi, and S. Nong, "Acute myocardial infarction and ascending aortic aneurysm in a child with Behçet's disease," Turkish Journal of Pediatrics, vol. 50, no. 1, pp. 81-85, 2008.

[81] Ş. Türkölmez, N. Gökçora, M. Alkan, and M. Ali Gürer, "Evaluation of myocardial perfusion in patients with Behçet's disease," Annals of Nuclear Medicine, vol. 19, no. 3, pp. 201206, 2005.

[82] I. H. Güllü, M. Benekli, H. Müderrisoğlu et al., "Silent myocardial ischemia in Behçet's disease," Journal of Rheumatology, vol. 23, no. 2, pp. 323-327, 1996.

[83] M. Fekih, S. Fennira, L. Ghodbane, and R. M. Zaouali, "Intracardiac thrombosis: unusual complication of Behcet's disease," La Tunisie Médicale, vol. 82, no. 8, pp. 785-790, 2004.
[84] A. Vivante, Y. Bujanover, J. Jacobson, S. Padeh, and Y. Berkun, "Intracardiac thrombus and pulmonary aneurysms in an adolescent with Behçet disease," Rheumatology International, vol. 29, no. 5, pp. 575-577, 2009.

[85] G. Vanhaleweyk, K. M. El-Ramahi, M. Hazmi, J. O. Sieck, L. Zaman, and M. Fawy, "Right atrial, right ventricular and left ventricular thrombi in (incomplete) Behcet's disease," European Heart Journal, vol. 11, no. 10, pp. 957-959, 1990.

[86] N. Mogulkoc, M. I. Burgess, and P. W. Bishop, "Intracardiac thrombus in Behcet's disease: a systematic review," Chest, vol. 118, no. 2, pp. 479-487, 2000.

[87] F. Atzeni, P. Sarzi-Puttini, A. Doria, L. Boiardi, N. Pipitone, and C. Salvarani, "Behçet's disease and cardiovascular involvement," Lupus, vol. 14, no. 9, pp. 723-726, 2005.

[88] M. Elqatni, Y. Sekkach, A. Abouzahir, and D. Ghafir, "Right atrium thrombus and pulmonary artery aneurysm in a man with behçet's disease," Internal Medicine, vol. 50, no. 3, pp. 263-264, 2011.

[89] I. Dincer, R. Dandachi, Y. Atmaca, C. Erol, N. Caglar, and D. Oral, "A recurrent right heart thrombus in a patient with Behçet's disease," Echocardiography, vol. 18, no. 1, pp. 15-18, 2001.

[90] I. Ben Ghorbel, Z. Ibn Elhadj, M. Khanfir et al., "Intracardiac thrombus in Behçet's disease. A report of three cases," Journal des Maladies Vasculaires, vol. 29, no. 3, pp. 159-161, 2004.

[91] A. G. Sayin, F. S. Vural, A. K. Bozkurt, B. Oz, and N. Uygun, "Right atrial thrombus mimicking myxoma and bilateral pulmonary artery aneurysms in a patient with Behcet's disease-a case report," Angiology, vol. 44, no. 11, pp. 915918, 1993.

[92] S. Hammami, S. Mahjoub, K. Ben-Hamda, R. Brahem, H. Gamra, and M. B. Farhat, "Intracardiac thrombus in Behçet's disease: two case reports," Thrombosis Journal, vol. 3, article no. 9, 2005.

[93] D. Özatli, T. Kav, I. C. Haznedaroğlu et al., "Cardiac and great vessel thrombosis in Behçet's disease," Internal Medicine, vol. 40, no. 1, pp. 68-72, 2001.

[94] F. Atalay, D. Ernam, F. Ökten, and N. Akar, "Elevated FVIII and FIX level in a Behçet's disease patient with intracardiac thrombosis and pulmonary arterial aneurysms," Thrombosis Research, vol. 115, no. 1-2, pp. 159-161, 2005.

[95] M. Cemri, A. Erkan, M. Ozdemir, and A. Cengel, "Behcet's disease with a large and free right atrial thrombus," European Journal of Echocardiography, vol. 3, no. 3, pp. 233-235, 2002.

[96] M. Baykan, S. Celik, C. Erdöl et al., "Behçet's disease with a large intracardiac thrombus: a case report," Heart, vol. 85, no. 4, article E7, 2001.

[97] C. Gürgün, E. Ercan, C. Ceyhan et al., "Cardiovascular involvement in Behçet's disease," Japanese Heart Journal, vol. 43, no. 4, pp. 389-398, 2002.

[98] K. Okada, K. Eishi, Y. Kitoh et al., "Huge aneurysm of the sinus of valsalva following infective endocarditis in Behcet's disease," Journal of Heart Valve Disease, vol. 6, no. 2, pp. 179180, 1997.

[99] D. L. Huong, B. Wechsler, T. Papo et al., "Endomyocardial fibrosis in Behcet's disease," Annals of the Rheumatic Diseases, vol. 56, no. 3, pp. 205-208, 1997.

[100] N. K. Eryol, R. Topsakal, A. Abaci, and A. Oǧuzhan, "A case of atrioventricular complete block due to Behçet's disease," Japanese heart journal, vol. 43, no. 6, pp. 697-701, 2002.

[101] O. Kirimli, O. Aslan, O. Göldeli et al., "Heart rate variability, late potentials and QT dispersion as markers of myocardial involvement in patients with Behcet's disease," Canadian Journal of Cardiology, vol. 16, no. 3, pp. 345-351, 2000. 
[102] R. Sarica-Kucukoglu, A. Akdag-Kose, M. Kayabali et al., "Vascular involvement in Behçet's disease: a retrospective analysis of 2319 cases," International Journal of Dermatology, vol. 45, no. 8, pp. 919-921, 2006.

[103] N. Düzgün, A. Ateş, O. T. Aydintuğ, Ö. Demir, and Ü. Ölmez, "Characteristics of vascular involvement in Behçet's disease," Scandinavian Journal of Rheumatology, vol. 35, no. 1, pp. 6568, 2006

[104] P. R. J. Ames, A. Steuer, A. Pap, and A. M. Denman, "Thrombosis in Behçet's disease: a retrospective survey from a single UK centre," Rheumatology, vol. 40, no. 6, pp. 652 655, 2001.

[105] A. Gürler, A. Boyvat, and Ü. Türsen, "Clinical manifestations of Behçet's disease: an analysis of 2147 patients," Yonsei Medical Journal, vol. 38, no. 6, pp. 423-427, 1997.

[106] A. N. Al-Dalaan, S. R. Al Balaa, K. El Ramahi et al., "Behcet's disease in Saudi Arabia," Journal of Rheumatology, vol. 21, no. 4, pp. 658-661, 1994.

[107] Y. Koc, I. Gullu, G. Akpek et al., "Vascular involvement in Behcet's disease," Journal of Rheumatology, vol. 19, no. 3, pp. 402-410, 1992.

[108] E. Seyahi and S. Yurdakul, "Behcet's syndrome and thrombosis," Mediterranean Journal of Hematology and Infectious Diseases, vol. 3, no. 1, Article ID e2011026, 2011.

[109] E. Kural-Seyahi, I. Fresko, N. Seyahi et al., "The long-term mortality and morbidity of Behçet syndrome: a 2-decade outcome survey of 387 patients followed at a dedicated center," Medicine, vol. 82, no. 1, pp. 60-76, 2003.

[110] G. Tomasson, P. A. Monach, and P. A. Merkel, "Thromboembolic disease in vasculitis," Current Opinion in Rheumatology, vol. 21, no. 1, pp. 41-46, 2009.

[111] R. T. Walker, A. B. Woodyer, and J. A. Dormandy, "Venous claudication. A report of 15 cases and a review of the literature," International Angiology, vol. 4, no. 3, pp. 365-367, 1985.

[112] U. Alpagut, M. Ugurlucan, and E. Dayioglu, "Major arterial involvement and review of Behcet's disease," Annals of Vascular Surgery, vol. 21, no. 2, pp. 232-239, 2007.

[113] A. Siva and S. Saip, "The spectrum of nervous system involvement in Behçet's syndrome and its differential diagnosis," Journal of Neurology, vol. 256, no. 4, pp. 513-529, 2009.

[114] G. Hatemi, A. Silman, D. Bang et al., "EULAR recommendations for the management of Behçet disease," Annals of the Rheumatic Diseases, vol. 67, no. 12, pp. 1656-1662, 2008.

[115] D. Saadoun, B. Wechsler, M. Resche-Rigon et al., "Cerebral venous thrombosis in Behçet's disease," Arthritis Care and Research, vol. 61, no. 4, pp. 518-526, 2009.

[116] H. Yazici and I. Fresko, "Behçet's disease and other autoinflammatory conditions: what's in a name?" Clinical and Experimental Rheumatology, vol. 23, no. 4, supplement 38, pp. S1-S2, 2005.

[117] A. Siva, O. H. Kantarci, S. Saip et al., "Behçet's disease: diagnostic and prognostic aspects of neurological involvement," Journal of Neurology, vol. 248, no. 2, pp. 95-103, 2001.

[118] G. Akman-Demir, P. Serdaroglu, and B. Tasçi, "Clinical patterns of neurological involvement in Behcet's disease: evaluation of 200 patients," Brain, vol. 122, no. 11, pp. 21712181, 1999.

[119] B. Wechsler, L. T. Du, and J. C. Piette, "Behçet's disease," The European journal of medicine, vol. 1, no. 7, pp. 387-390, 1992.

[120] D. Aguiar de Sousa, T. Mestre, and J. M. Ferro, "Cerebral venous thrombosis in Behçet's disease: a systematic review," Journal of Neurology, vol. 258, no. 5, pp. 719-727, 2011.
[121] I. Krause, L. Leibovici, D. Guedj, Y. Molad, Y. Uziel, and A. Weinberger, "Disease patterns of patients with Behcet's disease demonstrated by factor analysis," Clinical and Experimental Rheumatology, vol. 17, no. 3, pp. 347-350, 1999.

[122] S. Ketari Jamoussi, H. Chaaba, B. Ben Dhaou et al., "Arterial involvement in Behcet's disease: a series of 7 cases," Tunisie Medicale, vol. 87, no. 9, pp. 583-588, 2009.

[123] N. Kojima, Y. Sakano, S.-I. Ohki, and Y. Misawa, "Rapidly growing aortic arch aneurysm in Behçet's disease," Interactive Cardiovascular and Thoracic Surgery, vol. 12, no. 3, pp. 502504, 2011.

[124] K. Spiliotopoulos, B. Yanagawa, A. Crean, C. Overgaard, and S. J. Brister, "Surgical management of a left anterior descending pseudoaneurysm related to Behcet's disease," Annals of Thoracic Surgery, vol. 91, no. 3, pp. 912-914, 2011.

[125] J. V. Rico, F. G. Pedrajas, I. C. González, and R. J. Segura Iglesias, "Urgent endovascular treatment of a ruptured tibioperoneal pseudoaneurysm in Behet's disease," Annals of Vascular Surgery, vol. 25, no. 3, pp. 385.e11-385.e14, 2011.

[126] B. W. Ullery, A. Pochettino, G. J. Wang, B. M. Jackson, R. M. Fairman, and E. Y. Woo, "Celiac artery aneurysm repair in Behçet disease complicated by recurrent thoracoabdominal aortic aneurysms," Vascular and Endovascular Surgery, vol. 44, no. 2, pp. 146-149, 2010.

[127] B. Kisacik, T. Kasifoglu, S. Akay et al., "Ulnar artery aneurysm in a patient with Behçet's disease," Rheumatology International, vol. 30, no. 3, pp. 383-385, 2010.

[128] A. Yildirim, A. Isik, and S. Koca, "Subclavian artery pseudoaneurysm in Behcet's disease," Clinical Rheumatology, vol. 26, no. 7, pp. 1151-1154, 2007.

[129] S. Men, M. N. Ozmen, F. Balkanci, S. Boyacigil, and H. Akbari, "Superior mesenteric artery aneurysm in Behcet's disease," Abdominal Imaging, vol. 19, no. 4, pp. 333-334, 1994.

[130] O. Uzun, T. Akpolat, and L. Erkan, "Pulmonary vasculitis in Behçet disease: a cumulative analysis," Chest, vol. 127, no. 6, pp. 2243-2253, 2005.

[131] S. Benamour, B. Zeroual, R. Bennis, A. Amraoui, and S. Bettal, "Behcet's disease. 316 Cases," Presse Medicale, vol. 19, no. 32, pp. 1485-1489, 1990.

[132] S. Pay, T. Abbasov, H. Erdem et al., "Serum MMP-2 and MMP-9 in patients with Behçet's disease: Do their higher levels correlate to vasculo-Behçet's disease associated with aneurysm formation?" Clinical and Experimental Rheumatology, vol. 25, no. 4 SUPPL. 45, pp. S70-S75, 2007.

[133] H. Yazici, I. Fresko, and S. Yurdakul, "Behçet's syndrome: disease manifestations, management, and advances in treatment," Nature Clinical Practice Rheumatology, vol. 3, no. 3, pp. 148-155, 2007.

[134] K. T. Calamia, M. Schirmer, and M. Melikoglu, "Major vessel involvement in Behçet's disease: an update," Current Opinion in Rheumatology, vol. 23, no. 1, pp. 24-31, 2011.

[135] A. Gul, "Standard and novel therapeutic approaches to Behçet's disease," Drugs, vol. 67, no. 14, pp. 2013-2022, 2007.

[136] H. Yazici, H. Pazarli, C. G. Barnes et al., "A controlled trial OF azathioprine in Behcet's syndrome," New England Journal of Medicine, vol. 322, no. 5, pp. 281-285, 1990.

[137] V. Hamuryudan, Y. Özyazgan, N. Hizli et al., "Azathioprine in Behcet's syndrome: effects on long-term prognosis," Arthritis and Rheumatism, vol. 40, no. 4, pp. 769-774, 1997.

[138] D. Saadoun, B. Wechsler, C. Terrada et al., "Azathioprine in severe uveitis of Behçet's disease," Arthritis Care \& Research, vol. 62, no. 12, pp. 1733-1738, 2010. 
[139] P. A. Pacheco, S. R. J. Taylor, M. T. Cuchacovich, and G. V. Diaz, "Azathioprine in the management of autoimmune uveitis," Ocular Immunology and Inflammation, vol. 16, no. 4, pp. 161-165, 2008.

[140] G. Cocco, D. C. C. Chu, and S. Pandolfi, "Colchicine in clinical medicine. A guide for internists," European Journal of Internal Medicine, vol. 21, no. 6, pp. 503-508, 2010.

[141] H. Abdul-Hussien, R. Hanemaaijer, J. H. Verheijen, J. H. van Bockel, R. H. Geelkerken, and J. H. N. Lindeman, "Doxycycline therapy for abdominal aneurysm: improved proteolytic balance through reduced neutrophil content," Journal of Vascular Surgery, vol. 49, no. 3, pp. 741-749, 2009.

[142] K. Yasui, "Thalidomide as immunomodulatory drug: pharmacological actions and its indications," Japanese Journal of Clinical Immunology, vol. 33, no. 5, pp. 229-233, 2010.

[143] B. Ladizinski, E. J. Shannon, M. R. Sanchez, and W. R. Levis, "Thalidomide and analogues: potential for immunomodulation of inflammatory and neoplastic dermatologic disorders," Journal of Drugs in Dermatology, vol. 9, no. 7, pp. 814-826, 2010.

[144] L. Caspary, "Vasculitides of large vessels," Vasa, vol. 40, no. 2, pp. 89-98, 2011.

[145] P. Caramaschi, G. Poli, A. Bonora et al., "A study on thrombophilic factors in Italian Behcet's patients," Joint Bone Spine, vol. 77, no. 4, pp. 330-334, 2010.

[146] N. Ş. Yaşar, F. Salgür, D. Ü. Cansu, T. Kaşifoğlu, and C. Korkmaz, "Combined thrombophilic factors increase the risk of recurrent thrombotic events in Behcet's disease," Clinical Rheumatology, vol. 29, no. 12, pp. 1367-1372, 2010.

[147] A. B. Haghighi and A. Safari, "Proposing an algorithm for treatment of different manifestations of neuro-Behcet's disease," Clinical Rheumatology, vol. 29, no. 6, pp. 683-686, 2010.

[148] T. El Houari, L. Oukerraj, L. Ghzaiel et al., "Management of Behçet disease with multiple complications," Hellenic Journal of Cardiology, vol. 50, no. 5, pp. 420-422, 2009.

[149] S. Ozen, Y. Bilginer, N. Besbas, N. A. Ayaz, and A. Bakkaloglu, "Behçet disease: treatment of vascular involvement in children," European journal of pediatrics, vol. 169, no. 4, pp. 427430, 2010.

[150] M. Piga, F. Puchades, I. Mayo, and D. D'Cruz, "Successful thrombolytic therapy for recurrent right ventricular thrombosis in Behçet's disease," Clinical and Experimental Rheumatology, vol. 28, no. 4, supplement 60, pp. S76-S78, 2010.

[151] F. El Louali, A. Tamdy, A. Soufiani et al., "Cardiac thrombosis as a manifestation of Behçet syndrome," Texas Heart Institute Journal, vol. 37, no. 5, pp. 568-571, 2010.

[152] Z. Khammar, R. Berrady, A. Boukhrissa et al., "Intracardiac thrombosis in Behçet disease: clinical presentation and outcome of three cases," Journal des Maladies Vasculaires, vol. 36, no. 4, pp. 270-273, 2011.

[153] S. Volpinari, C. Monaldini, J. G. Capone et al., "Headache in Behçet's disease: case reports and literature review," Reumatismo, vol. 61, no. 3, pp. 174-181, 2009.

[154] A. Sayed, H. Elwan, F. Fouad et al., "Behcet extracranial carotid aneurysms: is there still a role for ligation?" European Journal of Vascular and Endovascular Surgery, vol. 39, no. 1, pp. 17-22, 2010.

[155] R. Attia, J. Reidy, D. D’Cruz, and L. Lang-Lazdunski, "Pulmonary artery ligation with lung preservation in Behcet disease: report of a case with prolonged survival," Journal of
Thoracic and Cardiovascular Surgery, vol. 139, no. 4, pp. e93e95, 2010.

[156] W. H. Kim, D. Choi, J. S. Kim, Y. G. Ko, Y. Jang, and W. H. Shim, "Effectiveness and safety of endovascular aneurysm treatment in patients with vasculo-Behçet disease," Journal of Endovascular Therapy, vol. 16, no. 5, pp. 631-636, 2009.

[157] S. S. Nitecki, A. Ofer, T. Karram, H. Schwartz, A. Engel, and A. Hoffman, "Abdominal aortic aneurysm in Behçet's disease: new treatment options for an old and challlenging problem," Israel Medical Association Journal, vol. 6, no. 3, pp. 152-155, 2004.

[158] B.-L. Ho, R.-T. Lin, Y.-F. Chen, and H.-F. Lin, "Behcet's disease with involvement of major arteries: a case report," Acta Neurologica Taiwanica, vol. 17, no. 4, pp. 253-257, 2008.

[159] G. Espinosa, I. Blanco, J. M. Antón, M. Sánchez, P. Macchiarini, and J. A. Barberà, "Chronic thromboembolic pulmonary hypertension in Behçet's disease: effectiveness of endarterectomy," Clinical and Experimental Rheumatology, vol. 28, no. 4, supplement 60, pp. S79-S81, 2010.

[160] P. Porcu, O. Chavanon, B. Bertrand et al., "Giant aneurysm of the proximal segment of the left anterior descending artery in a patient with Behçet's disease-a combined approach," Canadian Journal of Cardiology, vol. 24, no. 10, pp. e73-e74, 2008.

[161] M. Alidoosti, M. Marzban, and P. Yazdanifard, "Endovascular repair of post-surgical pseudoaneurysm of suprarenal abdominal aorta in a patient with Behcet's disease," International Angiology, vol. 27, no. 4, pp. 350-352, 2008.

[162] S. W. Han, G. W. Kim, J. Lee, Y. J. Kim, and Y. M. Kang, "Successful treatment with stent angioplasty for Budd-Chiari syndrome in Behçet's disease," Rheumatology International, vol. 25, no. 3, pp. 234-237, 2005.

[163] C. W. Liu, W. Ye, B. Liu, R. Zeng, W. Wu, and M. D. Dake, "Endovascular treatment of aortic pseudoaneurysm in Behçet disease," Journal of Vascular Surgery, vol. 50, no. 5, pp. 1025-1030, 2009.

[164] S. Yilmaz and K. A. Cimen, "Pulmonary artery aneurysms in Behçet's disease," Rheumatology International, vol. 30, no. 10, pp. 1401-1403, 2010.

[165] N. Pipitone, I. Olivieri, F. Cantini, G. Triolo, and C. Salvarani, "New approaches in the treatment of Adamantiades-Behçet's disease," Current Opinion in Rheumatology, vol. 18, no. 1, pp. 3-9, 2006.

[166] K. Baki, P. M. Villiger, D. Jenni, T. Meyer, and J. H. Beer, "Behçet's disease with life-threatening haemoptoe and pulmonary aneurysms: complete remission after infliximab treatment," Annals of the Rheumatic Diseases, vol. 65, no. 11, pp. 1531-1532, 2006.

[167] E. A. O’Leary, I. Sabahi, J. J. Ricotta, B. Walitt, and C. M. Akbari, "Femoral profunda artery aneurysm as an unusual first presentation of Behcet disease," Vascular and Endovascular Surgery, vol. 45, no. 1, pp. 98-102, 2011.

[168] C. Hidalgo-Tenorio, J. M. Sabio-Sánchez, P. J. P. Linares, L. M. Salmerón, E. Ros-Die, and J. Jiménez-Alonso, "Magic syndrome and true aortic aneurysm," Clinical Rheumatology, vol. 27, no. 1, pp. 115-117, 2008.

[169] F. Atzeni and P. Sarzi-Puttini, "Autoantibody production in patients treated with anti-TNF- $\alpha$," Expert Review of Clinical Immunology, vol. 4, no. 2, pp. 275-280, 2008.

[170] I. Altorjay, Z. Veréb, Z. Serfozo et al., "Anti-TNF- $\alpha$ antibody (infliximab) therapy supports the recovery of enos and VEGFR2 protein expression in endothelial cells," International Journal of Immunopathology and Pharmacology, vol. 24, no. 2, pp. 323-335, 2011. 
[171] A. Syngle, K. Vohra, A. Sharma, and L. Kaur, "Endothelial dysfunction in ankylosing spondylitis improves after tumor necrosis factor- $\alpha$ blockade," Clinical Rheumatology, vol. 29, no. 7, pp. 763-770, 2010.

[172] F. Davatchi, H. Shams, M. Rezaipoor et al., "Rituximab in intractable ocular lesions of Behcet's disease; randomized single-blind control study (pilot study)," International Journal of Rheumatic Diseases, vol. 13, no. 3, pp. 246-252, 2010.

[173] S. Sadreddini, H. Noshad, M. Molaeefard, and R. Noshad, "Treatment of retinal vasculitis in Behçt's disease with rituximab," Modern Rheumatology, vol. 18, no. 3, pp. 306308, 2008.

[174] U. Kaneko, T. Kishi, M. Kikuchi et al., "Two patients with childhood-onset Behcet's disease successfully treated by antitumor necrosis factor therapy," Japanese Journal of Clinical Immunology, vol. 33, no. 3, pp. 157-161, 2010.

[175] M. F. Zhang, C. Zhao, X. Wen, H. Du, and Y. Zhao, "The short-term efficacy and safety treatment study of recurrent uveitis in Behcet disease with etanercept," Chinese Journal of Ophthalmology, vol. 46, no. 2, pp. 145-150, 2010.

[176] Z. Szekanecz, G. Kerekes, and P. Soltész, "Vascular effects of biologic agents in RA and spondyloarthropathies," Nature Reviews Rheumatology, vol. 5, no. 12, pp. 677-684, 2009.

[177] I. Kötter, V. Hamuryudan, Z. E. A-Ztürk, and H. Yazici, "Interferon therapy in rheumatic diseases: state-of-the-art 2010," Current Opinion in Rheumatology, vol. 22, no. 3, pp. 278-283, 2010.

[178] K. Namba, K. H. Sonoda, H. Kitamei et al., "Granulocytapheresis in patients with refractory ocular Behcet's disease," Journal of clinical apheresis, vol. 21, no. 2, pp. 121-128, 2006.

[179] T. Daikeler, I. Kötter, C. B. Tyndall et al., "Haematopoietic stem cell transplantation for vasculitis including Behçet's disease and polychondritis: a retrospective analysis of patients recorded in the European Bone Marrow Transplantation and European League Against Rheumatism databases and a review of the literature," Annals of the Rheumatic Diseases, vol. 66, no. 2, pp. 202-207, 2007.

[180] M. T. Inanc, N. Kalay, T. Heyit et al., "Effects of atorvastatin and lisinopril on endothelial dysfunction in patients with Behçet's disease," Echocardiography, vol. 27, no. 8, pp. 9971003, 2010. 

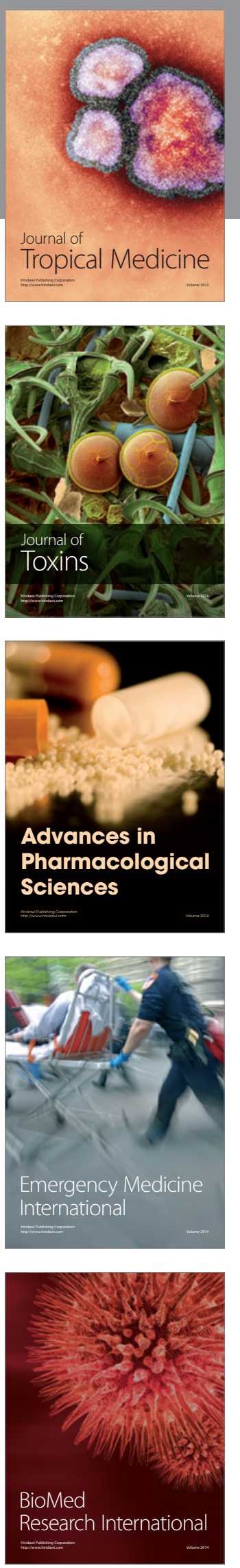
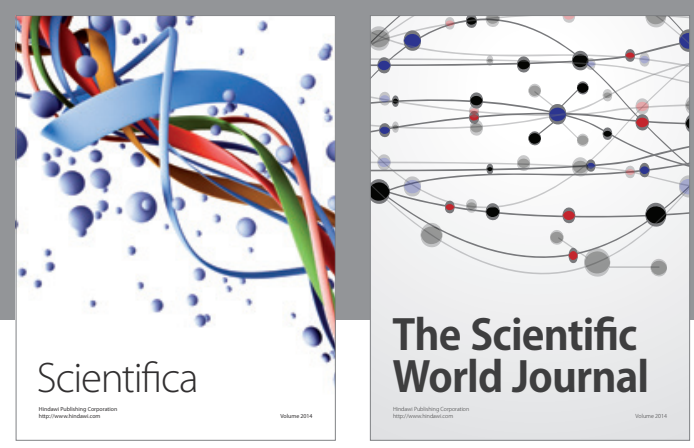

The Scientific World Journal
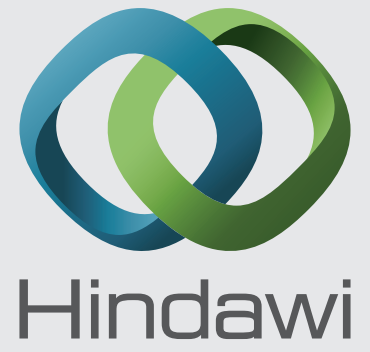

Submit your manuscripts at

http://www.hindawi.com
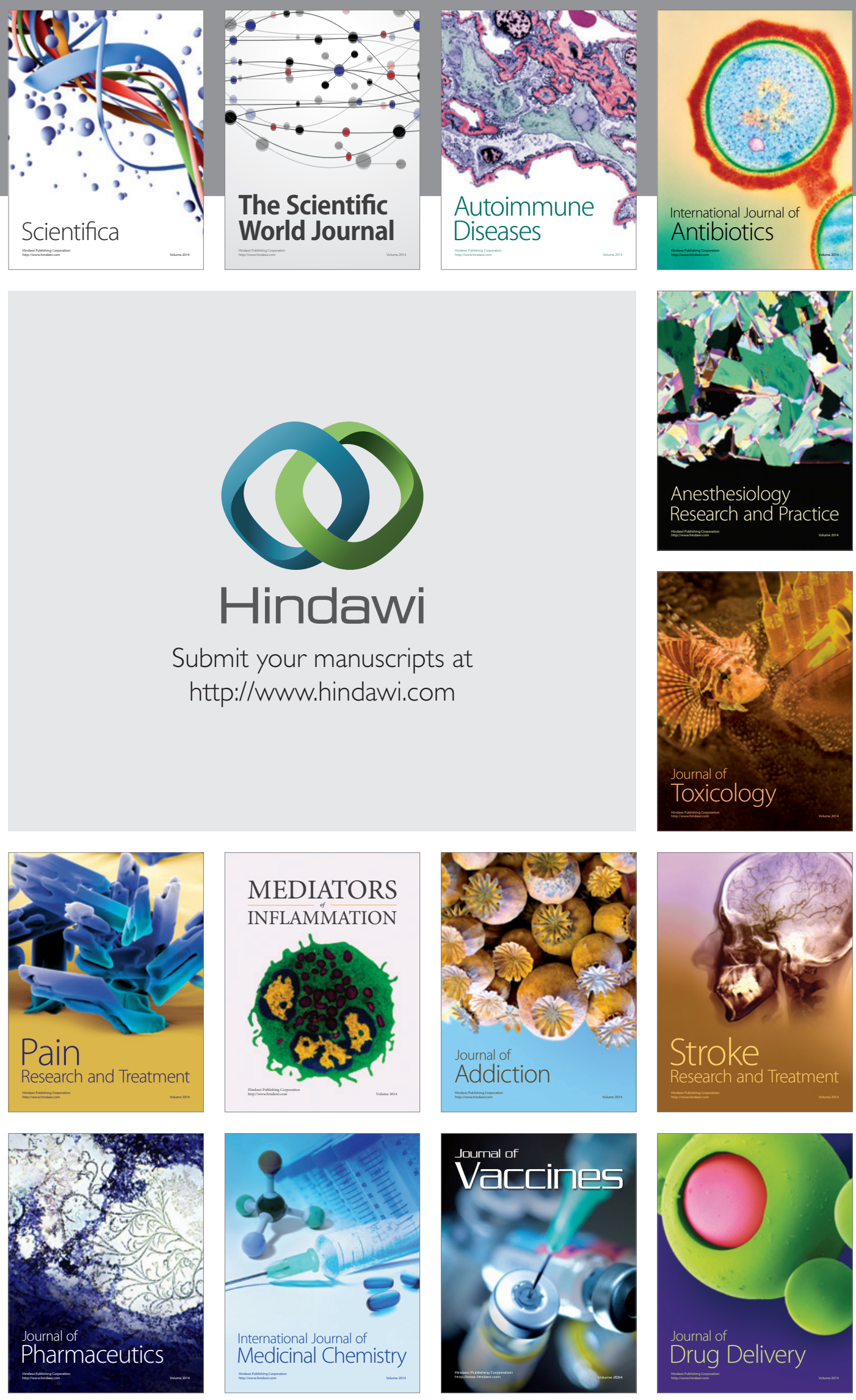